\title{
Fluorescent gelators for detection of explosives
}

\author{
Kenji Hanabusa, ${ }^{11,2}$ Shingo Takata, ${ }^{1}$ Masafumi Fujisaki, ${ }^{3}$ Yasushi Nomura, ${ }^{3}$ and Masahiro Suzuki ${ }^{1}$ \\ ${ }^{1}$ Interdisciplinary Graduate School of Science and Technology, Shinshu University, Ueda, 386-8567 \\ ${ }^{2}$ Division of Frontier Fibers, Institute for Fiber Engineering, ICCER, Shinshu University, Ueda, 386-8567 \\ ${ }^{3}$ Faculty of Textile Science \& Technology, Shinshu University, Ueda, 386-8567 \\ E-mail: hanaken@shinshu-u.ac.jp
}

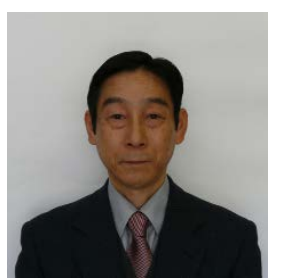

Kenji Hanabusa

In 1979, Kenji Hanabusa started his academic carrier at Shinshu University as an Assistant Professor. He received Ph.D. from Osaka University in 1981 in Japan. In 1987, he was promoted to an Associate Professor, and since 1999, he has been a Full Professor in the Interdisciplinary Graduate School of Science and Technology at Shinshu University. His research interest is the development of low-molecular weight gelators and thickeners on the basis of supramolecular chemistry.

\begin{abstract}
Carbazole-, quinoline-, benzothiazole-, and stilbenecontaining fluorescent gelators are synthesized by connecting gelation-driving segments, and their gelation abilities are studied with 13 solvents. Fibrous thin-layer films are prepared on quartz plates from the solutions or gels, and they are studied as chemosensors for explosives. Fluorescence quenching of the films upon exposure to saturated TNT or RDX vapor is used to evaluate the abilities of the films to detect explosives. The relationship between the thickness of the thin-layer film and the quenching efficiency upon exposure to TNT is studied. The morphologies of the thin-layer films are observed by dynamic force mode scanning probe microscopy and discussed with regard to their fluorescence quenching. The interactions among chromophores in the gels, thin-layer films, and solutions are studied by variable-temperature spectroscopy. The mechanism of TNT detection is discussed from the viewpoint of the HOMO and LUMO energy levels.
\end{abstract}

\section{Introduction}

The recent rise of terrorism has become a matter of grave concern owing to the immense damage that can be caused by explosives. Scientists, chemists in particular, have developed methods for the rapid detection of explosives. Several methods have been practically applied to explosives detection, including ion-mobility spectrometry, neutron backscattering, and explosive-detecting dogs. However, these methods suffer from many problems such as the need for non-portable heavy instruments, technicians for operation (e.g., radiographers), and high cost. A simple approach that utilizes reagents to detect vapors from explosives is an attractive alternative that is small, lightweight, and low-cost. Recently, Swager et al. ${ }^{1}$ successfully detected nitro-aromatics using conjugated polymers containing pentiptycene. Takeuchi et al. ${ }^{2}$ reported the detection of TNT vapor using the quenching of donor-acceptor-substituted stilbenes containing chiral binaphthyl groups. Liu et al. ${ }^{3}$ reported a fluorescent sensor for TNT using electrospun nanofibrous films of porphyrin. Zang et al., ${ }^{4}$ Müllen et al., ${ }^{5,6}$ and Han et al. ${ }^{7}$ successfully detected TNT using carbazole backbone-based fluorescent compounds with amorphous morphologies owing to oligomers, polymers, and dendrimers, respectively. Ajayaghosh et al. ${ }^{8}$ examined oligo(p-phenylenevinylene)-based gelators for TNT detection. Bhattacharya et al. ${ }^{9}$ reported the detection of 2,4,6-trinitrophenol in solutions by monitoring the fluorescence quenching of a $p$-phenylenevinylene-based probe.

In recent years, several researchers have shown considerable interest in studying gelators that can physically gel water or organic solvents. Such gelators are of interest because they can immobilize substantial volumes of solvent. With advances in the area of supramolecular chemistry, several reports on gelators have been published in recent years. ${ }^{10-28}$ Gelators of lowmolecular-weight compounds have unique characteristics including good solubility upon heating and the ability to induce the smooth gelation of liquids at low concentration. Gelators are also characterized by thermally reversible sol-gel transitions. These features can be attributed to 3D network structures, which are built up through noncovalent interactions such as hydrogen bonding, electrostatic interaction, van der Waals interaction, and $\pi-\pi$ interaction. Although several gelators have already been used as hardeners for spilled fluids and cooking oils, cosmetic materials, and thickeners for paint, recent gelator research has focused on applications such as drug delivery in biomaterials, ${ }^{29,30}$ scaffold materials for cells in tissue engineering, ${ }^{31,32}$ sensors $^{33-36}$, templates for the synthesis of inorganic nanostructures, ${ }^{37-41}$ auxiliary agents for producing organic electronics, ${ }^{42,43}$ and electrolytes that prevent liquid leakage. ${ }^{44}$

Over the last two decades, we have developed many lowmolecular-weight gelators and proposed the concept of a "gelation-driving segment." This gelation-driving segment is expected to be a useful tool for developing various types of gelators. ${ }^{45}$

In this study, we report the synthesis of fluorescent gelators using gelation-driving segments, and we employ fibrous thinlayer films based on the gelators as chemosensors for the detection of explosives. One of the most important features of gelators is their formation of gels with self-assembled fibers instead of crystals. Thin-layer films derived from gels have high surface areas due to the formation of fibrous aggregates, which is an advantage for sensor applications. We employed carbazole, quinoline, benzothiazole, and stilbene as the fluorescent segments. As the oxidative explosives, we focused on TNT and 
RDX, which are the main components of plastic explosives.

\subsection{Instrumentation}

\section{Experimental}

Elemental analysis was performed with a Perkin-Elmer 240B analyzer. Infrared spectra were recorded on a Jasco FTIR7300 spectrometer using $\mathrm{KBr}$ plate. UV-vis and fluorescence spectra were recorded on a Jasco V-570UV/VIS/NIR and a Jasco FP-6300. Dynamic force mode (DFM) of scanning probe microscope was done with a SII SPA-4001. Thickness of films was measured by a Yamato Scientific Alpha-Step D-600. Ionization potential was measured by a Riken Keiki photoemission spectrometer AC-2.

\subsection{Synthesis of fluorescent gelators}

Carbz-1: The preparation of this compound was reported in our previous paper. ${ }^{46}$

Carbz-2: A mixture of 7.03 g (20 mmol) of 11-(9H-Carbzol-9yl)undecanoic acid, $477.37 \mathrm{~g}$ (20 mmol) of L-valylaminooctadecane, $2.28 \mathrm{~g} \quad(22 \mathrm{mmol})$ of DIPC $\left(N, N^{\prime}-\right.$ diisopropylcarbodiimide), $2.44 \mathrm{~g}$ (20 mmol) of DMAP (4dimethylaminopyridine), and $100 \mathrm{~mL}$ of dichloromethane was refluxed overnight. Chloroform $(100 \mathrm{~mL})$ was added to the reaction mixture and an insoluble matter was removed. The resulting filtrate was washed with $100 \mathrm{~mL}$ of $1 \mathrm{M}$ hydrochloric acid, followed by $100 \mathrm{~mL}$ of water and dried. After evaporating, recrystallization from methanol/ethanol (7:3) gave $8.02 \mathrm{~g}$ (57\%) of Carbz-2. $\mathrm{R}_{\mathrm{f}}=0.9$ (chloroform, alumina); IR $\left(\mathrm{KBr}, \mathrm{cm}^{-1}\right)$ : 3289 ( $v$ NH amide A), 1631 ( $\mathrm{C}=\mathrm{O}$ amide I), 748, 719 (Carbazole); Found: C 78.72, H 11.26, N 6.13\%. Calcd for $\mathrm{C}_{46} \mathrm{H}_{75} \mathrm{~N}_{3} \mathrm{O}_{2}$ : C 78.69, H 10.77, N 5.98\%.

Carbz-3: This compound was obtained from a mixture of 0.88 g (2.5 mmol) of 11-(9H-Carbzol-9-yl)undecanoic acid, $1.24 \mathrm{~g}$ (2.5 mmol) of L-isoleucyl-L-isoleucylaminooctadecane, ${ }^{46} 0.35$ $\mathrm{g}(2.75 \mathrm{mmol})$ of DIPC, $0.31 \mathrm{~g}$ ( $2.5 \mathrm{mmol})$ of DMAP, and $20 \mathrm{~mL}$ of dichloromethane by the similar procedure described in Carbz-2. Recrystallization from methanol gave $0.92 \mathrm{~g}$ (44\%) of Carbz-3. $\mathrm{R}_{\mathrm{f}}=0.82$ (chloroform, alumina); IR $\left(\mathrm{KBr}, \mathrm{cm}^{-1}\right)$ : 3283 ( $v \mathrm{NH}$ amide A), 1633 ( $\mathrm{vC}=\mathrm{O}$ amide I), 747, 720 (Carbazole); Found: C 76.36, H 11.05, N 6.54\%. Calcd for $\mathrm{C}_{53} \mathrm{H}_{88} \mathrm{~N}_{4} \mathrm{O}_{3}$ : C 76.76, H 10.70, N 6.76\%.

Carbz-4: To a solution of $8.36 \mathrm{~g}(50 \mathrm{mmol})$ of carbazole and $2.87 \mathrm{~g}(50 \mathrm{mmol})$ of potassium hydroxide in $500 \mathrm{~mL}$ of dry DMF, was added $9.05 \mathrm{~g}(50 \mathrm{mmol})$ of 6-bromohexanol and $0.83 \mathrm{~g}$ (5 mmol) of potassium iodide. The resulting mixture was stirred overnight under an argon atmosphere. The mixture was poured to iced water and the precipitated matter was filtered off, washed with water. Recrystallization from $400 \mathrm{~mL}$ of methanol gave 11(9H-Carbzol-9-yl)hexanol in a yield of $10.22 \mathrm{~g}$ (76\%). $\mathrm{R}_{\mathrm{f}}=0.25$ (chloroform, silica gel). A mixture of $2.62 \mathrm{~g}(10 \mathrm{mmol})$ of cyclo(L-asparaginyl-L-phenylalanyl), ${ }^{47} 2.67 \mathrm{~g}(10 \mathrm{mmol})$ of $11-(9 \mathrm{H}-$ Carbzol-9-yl)hexanol, $3.24 \mathrm{~g}$ (11 mmol) of DPTS (4dimethylamino pyridinium $p$-toluenesulfonate), $1.38 \mathrm{~g}$ (11 mmol) of DIPC, and $30 \mathrm{~mL}$ of dry DMF was stirred overnight at $35^{\circ} \mathrm{C}$. After evaporating DMF, the residue was added to icewater. Recrystallization from $400 \mathrm{~mL}$ of 1-propanol gave $2.76 \mathrm{~g}$ (54\%) of Carbz-4. IR ( $\left.\mathrm{KBr}, \mathrm{cm}^{-1}\right): 1740$ ( $\mathrm{vC}=\mathrm{O}$ ester), 1671( $\mathrm{vC}=\mathrm{O}$ amide I), 750, 731 (Carbazole); Found: $\mathrm{C} 71.47, \mathrm{H}$ 6.43, N 8.37\%. Calcd for $\mathrm{C}_{31} \mathrm{H}_{33} \mathrm{~N}_{3} \mathrm{O}_{4}$ : C 72.78, H 6.50, N 8.21\%. Carbz-5: A mixture of $4.03 \mathrm{~g}$ (11.5 mmol) of 11-(9H-Carbzol9-yl)undecanoic acid, $0.66 \mathrm{~g}(5.74 \mathrm{mmol})$ of trans-(1R,2R)diaminocyclohexane, $1.59 \mathrm{~g}$ (12.6 mmol) of DIPC, $1.40 \mathrm{~g}$ (11.5 mmol) of DMAP, and $20 \mathrm{~mL}$ of dichloromethane was refluxed overnight. After evaporation, the resulting product was recrystallized from $200 \mathrm{~mL}$ of 1-propanol. Yield $3.36 \mathrm{~g}$ (75\%); $\mathrm{R}_{\mathrm{f}}=0.65$ (chloroform, alumina); IR $\left(\mathrm{KBr}, \mathrm{cm}^{-1}\right): 1634(\mathrm{vC}=\mathrm{O}$ amide I), 751, 720 (Carbazole); Found: C 79.61, H 8.99, N
7.49\%. Calcd for $\mathrm{C}_{52} \mathrm{H}_{68} \mathrm{~N}_{4} \mathrm{O}_{2}$ : C 79.96, H 8.77, N 7.17\%.

Quino-1: The preparation of this compound was reported in our previous paper. ${ }^{46}$

Quino-2: A mixture of $0.64 \mathrm{~g}$ (4.4 mmol) of 8-hydroxyquinoline, $0.88 \mathrm{~g}(6.6 \mathrm{mmol})$ of potassium carbonate, $0.66 \mathrm{~g}$ ( $4.0 \mathrm{mmol})$ of potassium iodide, $1.70 \mathrm{~g}$ (4 mmol) of 6-bromohexyloxycyclo(L-asparaginyl-L-phenylalanyl), ${ }^{46}$ and $20 \mathrm{~mL}$ of dry DMF was stirred at $40^{\circ} \mathrm{C}$ overnight under an argon atmosphere. The mixture was poured to iced water and the precipitated matter was filtered off, washed with water, and dried. A crude product obtained by recrystallization from ethyl acetate was purified by column chromatography on silica gel (elution with chloroform/methanol = 9:1; Rf = 0.7). Yield $0.56 \mathrm{~g}(29 \%)$. IR $\left(\mathrm{KBr}, \mathrm{cm}^{-1}\right): 1740$ ( $\mathrm{vC}=\mathrm{O}$ ester), $1671(\mathrm{vC}=\mathrm{O}$ amide $\mathrm{I}), 1108$ (quinoline); Found: C 67.36, H 6.41, N 8.44\%. Calcd for $\mathrm{C}_{28} \mathrm{H}_{31} \mathrm{~N}_{3} \mathrm{O}_{5}$ : C 68.69, H 6.38, N 8.58\%.

Quino-3: This compound was obtained from a mixture of 0.64 $\mathrm{g}(4.4 \mathrm{mmol})$ of 8-hydroxyquinoline, $0.88 \mathrm{~g}(6.6 \mathrm{mmol})$ of potassium carbonate, $0.66 \mathrm{~g}$ ( $4.0 \mathrm{mmol})$ of potassium iodide, $1.98 \mathrm{~g} \mathrm{(4} \mathrm{mmol)} \mathrm{of} \mathrm{11-bromoundecyloxycyclo(L-asparaginyl-L-}$ phenylalanyl), and $20 \mathrm{~mL}$ of dry DMF by the similar procedure described in Quino-2. Recrystallization from ethanol gave 1.46 $\mathrm{g}(65 \%)$ of Quino-3. $\mathrm{R}_{\mathrm{f}}=0.9$ (chloroform/methanol $=9: 1$, silica gel); IR ( $\left.\mathrm{KBr}, \mathrm{cm}^{-1}\right)$ : 1741 ( $\mathrm{vC}=\mathrm{O}$ ester), $1671(\mathrm{vC}=\mathrm{O}$ amide I), 1101 (quinoline); Found: C 71.67, H 7.98, N 6.87\%. Calcd for $\mathrm{C}_{33} \mathrm{H}_{41} \mathrm{~N}_{3} \mathrm{O}_{5}$ : C 70.82, H 7.38, N 7.51\%.

Quino-4: This compound was obtained from a mixture of 0.64 $\mathrm{g}(4.4 \mathrm{mmol})$ of 8-hydroxyquinoline, $0.88 \mathrm{~g}(6.6 \mathrm{mmol})$ of potassium carbonate, $0.66 \mathrm{~g}$ ( $4.0 \mathrm{mmol})$ of potassium iodide, $1.47 \mathrm{~g} \quad(2.0 \mathrm{mmol})$ of trans-(1R,2R)-bis(11-bromoundecanoylamino)cyclohexane, ${ }^{46}$ and $20 \mathrm{~mL}$ of dry DMF by the similar procedure described in Quino-2. A crude product obtained by recrystallization from $70 \mathrm{~mL}$ of acetone was purified by column chromatography on alumina (elution with chloroform; $\mathrm{Rf}=0.7$ ). Quino-4 was obtained by recrystallization from $40 \mathrm{~mL}$ of acetone in a yield of $1.25 \mathrm{~g}$ (85\%). IR ( $\left.\mathrm{KBr}, \mathrm{cm}^{-1}\right)$ : 1638 ( $\mathrm{vC}=\mathrm{O}$ amide I), 1108 (quinoline); Found: C 73.25, H 8.96, N 7.35\%. Calcd for $\mathrm{C}_{46} \mathrm{H}_{64} \mathrm{~N}_{4} \mathrm{O}_{4}$ : C 74.96, H 8.75, N 7.60\%.

Benth-1, Benth-2, and Benth-3: These compounds were prepared according to our previous paper. ${ }^{46}$

Stilb-1: A mixture of $2.16 \mathrm{~g}$ (10 mmol) of 4-nitrobenzyl bromide

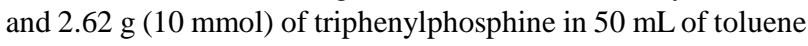
was refluxed for $6 \mathrm{~h}$. After evaporating toluene, the residue was dried in vacuo. 4-Dimethylaminobenzaldehyde (1.49 g, 10 $\mathrm{mmol}), 3.69 \mathrm{~g}$ ( $10 \mathrm{mmol})$ of tetrabutylammonium iodide, and 70 $\mathrm{mL}$ of $\mathrm{CH}_{2} \mathrm{Cl}_{2}$ were added to the residue. The resulting solution was added dropwise to a saturated solution of potassium carbonate in $100 \mathrm{~mL}$ of water, and then refluxed overnight. The separated organic layer after standing was washed with water twice, and dried with $\mathrm{MgSO}_{4}$, followed by evaporated. A crude product was purified by column chromatography on silica gel (elution with chloroform; $\mathrm{Rf}=0.70$ ). Recrystallization from a mixture of $40 \mathrm{~mL}$ of THF and $20 \mathrm{~mL}$ of hexane gave $1.18 \mathrm{~g}$ (44\%) of 4'-dimethylamino-4-nitrostilbene.

A mixture of $0.54 \mathrm{~g}(2.0 \mathrm{mmol})$ of 4'-dimethylamino-4nitrostilbene and $1.13 \mathrm{~g}(10 \mathrm{mmol})$ of $\mathrm{SnCl}_{2} / 2 \mathrm{H}_{2} \mathrm{O}$ in $40 \mathrm{~mL}$ of ethanol was refluxed for $24 \mathrm{~h}$ under an argon atmosphere. The cooled mixture was poured to $\sim 30 \mathrm{~g}$ of ice and then $2 \mathrm{~g}$ of $\mathrm{NaHCO}_{3}$ was added by portions. The matter was extracted with ethyl acetate and washed with water twice. The obtained crude product after evaporation was purified by column chromatography on alumina (elution with chloroform; $\mathrm{Rf}=0.65$ ). Recrystallization from ethanol/hexane gave 4-amino-4'dimethylaminostilbene in a yield of $0.28 \mathrm{~g}$ (59\%). Found: C 80.44, H 7.80, N 11.42\%. Calcd for $\mathrm{C}_{16} \mathrm{H}_{18} \mathrm{~N}_{2}$ : C 80.63, H 7.61, 
N $11.75 \%$.

A mixture of $0.48 \mathrm{~g}(2.0 \mathrm{mmol})$ of 4 -amino-4'dimethylaminostilbene and $1.19 \mathrm{~g}(2.0 \mathrm{mmol})$ of $\mathrm{N}$-(6isocyanato-trimethylhexylaminocarbonyl)-L-isoleucylaminooctadecane $^{48}$ in $30 \mathrm{~mL}$ of dry toluene was stirred at $85^{\circ} \mathrm{C}$ overnight under an argon atmosphere. After evaporating toluene, the purification from $60 \mathrm{~mL}$ of ethanol gave $1.18 \mathrm{~g}$ (71\%) of Stilb-1. $\mathrm{R}_{\mathrm{f}}=0.10$ (chloroform, silica gel); $\mathrm{IR}\left(\mathrm{KBr}, \mathrm{cm}^{-1}\right)$ : 1640 (C=O, amide I); Found: C 73.12, H 11.06, N 9.82\%. Calcd for $\mathrm{C}_{51} \mathrm{H}_{86} \mathrm{~N}_{6} \mathrm{O}_{3}$ : C 7369, H 10.43, N 10.11\%.

Stilb-2: A solution of $0.98 \mathrm{~g}$ ( $3.3 \mathrm{mmol}$ ) of triphosgene in $15 \mathrm{~mL}$ of $\mathrm{CH}_{2} \mathrm{Cl}_{2}$ was cooled in ice-water bath, and then equimolecular amounts of $2.42 \mathrm{~g} \mathrm{(10} \mathrm{mmol)} \mathrm{of} \mathrm{n-hexadecyl} \mathrm{alcohol} \mathrm{and} 0.79 \mathrm{~g}$ (10 mmol) of pyridine were added by small portions. The mixture was stirred for $48 \mathrm{~h}$ at room temperature, evaporated, and dried. The resulting matter was treated by $20 \mathrm{~mL}$ of hot THF and $\mathrm{NEt}_{3} / \mathrm{HCl}$ was removed. After evaporating, the oily product was purified by vacuum distillation $\left(\sim 200^{\circ} \mathrm{C} / 3 \mathrm{mmHg}\right)$. $\mathrm{n}-$ Hexadecyl chloroformate was obtained in a yield of $2.26 \mathrm{~g}$ (74\%).

A mixture of $1.40 \mathrm{~g}(7.4 \mathrm{mmol})$ of L-isoleucine methyl ester hydrochloride, $1.62 \mathrm{~g}$ (16 mmol) of $\mathrm{NEt}_{3}$, and $35 \mathrm{~mL}$ of dry THF was cooled in ice-water bath, and then $2.26 \mathrm{~g}(7.4 \mathrm{mmol})$ of $\mathrm{n}$ hexadecyl chloroformate was added by small portions. After stirred for $4 \mathrm{~h}$ at ambient temperature, $\mathrm{NEt}_{3} / \mathrm{HCl}$ was removed. Recrystallization from $30 \mathrm{~mL}$ of ligroin gave $2.39 \mathrm{~g}$ (78\%) of $\mathrm{N}$ n-hexadecyloxycarbonyl-L-isoleucine methyl ester. The ester of $2.39 \mathrm{~g}$ was hydrolyzed in $1.5 \mathrm{~mL}$ of $4 \mathrm{M} \mathrm{NaOH}$ and $50 \mathrm{~mL}$ of methanol. The precipitate after neutralization was recrystallized from $30 \mathrm{~mL}$ of hexane to afford $2.52 \mathrm{~g}$ (85\%) of $N$-nhexadecyloxycarbonyl-L-isoleucine. $\mathrm{IR}\left(\mathrm{KBr}, \mathrm{cm}^{-1}\right)$ : $1717(\mathrm{C}=\mathrm{O}$, carboxylic acid), 1687 (C=O, urethane); Found: C 69.24, H 12.03, N 3.68\%. Calcd for $\mathrm{C}_{23} \mathrm{H}_{45} \mathrm{NO}_{4}$ : C 69.13, $\mathrm{H} 11.35, \mathrm{~N}$ $3.39 \%$.

A mixture of $0.31 \mathrm{~g} \quad(0.8 \mathrm{mmol})$ of $N$-nhexadecyloxycarbonyl-L-isoleucine, $0.21 \mathrm{~g}(0.8 \mathrm{mmol})$ of trans4-(4-aminostyryl)benzonitrile, ${ }^{49} 0.11 \mathrm{~g}(0.88 \mathrm{mmol})$ of DIPC, $0.10 \mathrm{~g}(0.8 \mathrm{mmol})$ of DMAP, and $25 \mathrm{~mL}$ of dichloromethane was stirred at $35^{\circ} \mathrm{C}$ overnight. After evaporating, the purification from $30 \mathrm{~mL}$ of ethanol gave $0.63 \mathrm{~g}(52 \%)$ of Stilb-2. $\mathrm{R}_{\mathrm{f}}=0.12$ (chloroform, silica gel); IR(KBr, $\left.\mathrm{cm}^{-1}\right)$ : $1693(\mathrm{C}=\mathrm{O}$, urethane); 1659 (C=O, amide); Found: C 75.74, H 9.28, N 7.11\%. Calcd for $\mathrm{C}_{38} \mathrm{H}_{55} \mathrm{~N}_{3} \mathrm{O}_{3}$ : C 75.83, H 9.21, N 6.98\%.

Stilb-3: This compound was obtained from a mixture of $0.80 \mathrm{~g}$ (2.0 mmol) of $N$-n-hexadecyloxycarbonyl-L-isoleucine, $0.21 \mathrm{~g}$ (1.0 mmol) of 4-amino-4'-aminostilbene, $0.28 \mathrm{~g}(2.2 \mathrm{mmol})$ of DIPC, $0.25 \mathrm{~g}(2.0 \mathrm{mmol})$ of DMAP, and $25 \mathrm{~mL}$ of dichloromethane by the similar procedure described in Stilb-2. Recrystallization from $30 \mathrm{~mL}$ of 1-propanol gave $0.63 \mathrm{~g} \mathrm{(65 \% )}$ of Stilb-3. $\mathrm{R}_{\mathrm{f}}=0.62$ (chloroform, alumina); IR $\left(\mathrm{KBr}, \mathrm{cm}^{-1}\right)$ : 1691 (C=O, urethane); 1662 (C=O, amide); Found: C 74.16, H 10.67, N 6.07\%. Calcd for $\mathrm{C}_{60} \mathrm{H}_{100} \mathrm{~N}_{4} \mathrm{O}_{6}$ : C 74.03, H 10.35, N 5.76\%. Stilb-4: A mixture of $0.25 \mathrm{~g}(2.0 \mathrm{mmol})$ of $p$ hydroxybenzaldehyde, $0.84 \mathrm{~g}$ (3.2 $\mathrm{mmol})$ of potassium carbonate, $0.33 \mathrm{~g}(2.0 \mathrm{mmol})$ of potassium iodide, $1.26 \mathrm{~g}$ (2.0 mmol) of $N$-11-bromoundecanoyl-L-isoleucylaminooctadecane, ${ }^{49}$ and $40 \mathrm{~mL}$ of dry DMF was stirred at $60^{\circ} \mathrm{C}$ overnight under an argon atmosphere. The mixture was poured to iced water and the precipitated matter was filtered off, washed with water, and dried. A crude product was recrystallized from $40 \mathrm{~mL}$ of methanol. 11-(4-Formylphenoxy)undecanoyl-Lisoleucylaminooctadecane was obtained in a yield of $1.18 \mathrm{~g}$ (88\%). $\mathrm{R}_{\mathrm{f}}=0.78$ (chloroform, alumina); IR $\left(\mathrm{KBr}, \mathrm{cm}^{-1}\right)$ : 1691 (C=O, aldehyde); 1633 (C=O, amide); Found: C 75.31, H 11.01, $\mathrm{N} 4.08 \%$. Calcd for $\mathrm{C}_{42} \mathrm{H}_{74} \mathrm{~N}_{2} \mathrm{O}_{4}$ : C 75.17, $\mathrm{H}$ 11.12, N 4.17\%.

A solution of $0.39 \mathrm{~g}(2.0 \mathrm{mmol})$ of $p$-cyanobenzyl bromide,
$0.53 \mathrm{~g}$ ( $2.0 \mathrm{mmol})$ of triphenylphosphine, and $20 \mathrm{~mL}$ of toluene was refluxed for $4 \mathrm{~h}$. After evaporating, the matter was dissolved in $40 \mathrm{~mL}$ of DMF, and then $0.12 \mathrm{~g}(3.0 \mathrm{mmol})$ of $\mathrm{NaH}$ (assay $60 \%$ ) was added. The mixture was stirred at $40^{\circ} \mathrm{C}$ for $1 \mathrm{~h}$ under an argon atmosphere. 11-(4-Formylphenoxy)undecanoyl-Lisoleucylaminooctadecane $(1.0 \mathrm{~g}, 1.5 \mathrm{mmol})$ was added to the mixture and stirred at $40^{\circ} \mathrm{C}$ for $24 \mathrm{~h}$ under an argon atmosphere. The mixture was poured to iced water and the precipitated matter was filtered off, washed with water. Recrystallization from 40 $\mathrm{mL}$ of ethanol gave Stilb-4 in a yield of $0.92 \mathrm{~g}(80 \%)$. $\mathrm{R}_{\mathrm{f}}=0.78$ (chloroform, alumina); IR (KBr, $\left.\mathrm{cm}^{-1}\right)$ : 2225 (CN); disappearance of 1687 (C=O, aldehyde); Found: $\mathrm{C} 78.16, \mathrm{H}$ 10.60, N 5.24\%. Calcd for $\mathrm{C}_{50} \mathrm{H}_{79} \mathrm{~N}_{3} \mathrm{O}_{3}$ : C 77.97, $\mathrm{H} \mathrm{10.34,} \mathrm{N}$ $5.46 \%$.

TNT and RDX: These explosives were prepared carefully according to the literature ${ }^{50-52}$. TNT was obtained as pale yellow plate crystal by recrystallization from a mixture of tetrachloromethane and ethanol. RDX was obtained as colorless plate crystal by recrystallization from a mixture of acetone and ethanol. ${ }^{1} \mathrm{H}-\mathrm{NMR}$ for TNT (400 MHz, $\mathrm{CDCl}_{3}$, TMS, $\left.25^{\circ} \mathrm{C}\right): \delta=$ 8.84 (s, 2H), 2.72 (s, 3H). ${ }^{1} \mathrm{H}-\mathrm{NMR}$ for RDX (400 MHz, DMSO$\left.\mathrm{d} 6, \mathrm{TMS}, 25^{\circ} \mathrm{C}\right): \delta=6.10$ (s).

\subsection{Gelation test}

Gelation test was carried out by upside-down test tube method. The concentration for gelation test was fixed to be $40 \mathrm{mg} \mathrm{mL}^{-1}$ (gelator/solvent). A typical procedure is as follows: Forty milligrams of a sample and $1 \mathrm{~mL}$ of a solvent in a septum-capped test tube with internal diameter of $14 \mathrm{~mm}$ was heated until the solid dissolved. The resulting solution was cooled at $25^{\circ} \mathrm{C}$ for 1 $\mathrm{h}$ and then the gelation was checked visually. When no fluid ran down the wall of the test tube upon inversion of the test tube, we judged it to be gel.

\subsection{Preparation of thin-layer films as sensors and exposure} to saturated explosive vapor

Thin-layer films as chemosensor were prepared by directly dropcasting method. A typical procedure is as follows: The warm ethanol solution of Carbz-1 ( $3 \mu \mathrm{L}$ of $1.0 \times 10^{-3} \mathrm{M}$ ) was dropcasted on a quartz plate of $15 \mathrm{~W}$ x $2 \mathrm{D}$ x $50 \mathrm{H}$, followed by spincoated, and then dried in vacuo. Exposure to saturated explosive vapor was done in a glass tube vessel with a dimeter of $37 \mathrm{~mm}$ and a height of $110 \mathrm{~mm}$, in the bottom of which explosive was placed.

\subsection{Theoretical calculations}

The TNT was geometry-optimized in gas phase using the B3LYP/6-31G* method, and the HOMO and LUMO levels were calculated.

\section{Results and Discussion \\ 3.1. Fluorescent compounds and gelation abilities}

The structures of the carbazole-containing gelators (Carbz-1, Carbz-2, Carbz-3, Carbz-4, and Carbz-5) and the quinoline-containing gelators (Quino-1, Quino-2, Quino-3, and Quino-4) are shown in Scheme 1, and those of the benzothiazole-containing gelators (Benth-1, Benth-2, and Benth-3) and the stilbene-containing gelators (Stilb-1, Stilb-2, Stilb-3, and Stilb-4) are shown in Scheme 2. These compounds were prepared by Williamson synthesis or coupling reactions with gelation-driving segments developed by us. ${ }^{45}$ The compounds include an amino acid residue, trans-(1R,2R)diaminocyclohexane, and cyclo(L-asparaginyl-L-phenylalanyl) as gelation-driving segments.

Gelation tests were carried out using the upside-down testtube method. The concentrations were fixed at $40 \mathrm{mg} \mathrm{mL}^{-1}$ (gelator/solvent). Because this concentration is generally enough to cause physical gelation for good gelators. The results of the gelation tests with 13 solvents are summarized in Table 1 and 
Table 2. All compounds were too soluble in chloroform to act as gelators; in contrast, they were sparingly soluble in hexane. They failed to cause gelation in THF. Carbz-1, Carbz-2, Carbz-3, Quino-1, Benth-1, and Stilb-4 were excellent gelators in terms of the number of solvents that could be gelled. These results indicate that the amino acid-containing segment, especially alkanoyl-L-isoleucylaminooctadecane, is very useful for driving gelation. Considering that Carbz-4, Carbz-5, Quino-2, Quino3, Quino-4, Benth-2, and Benth-3 are not really good gelators, we can conclude that trans-(1R,2R)-diaminocyclohexane and cyclo(L-asparaginyl-L-phenylalanyl) are not suitable as gelationdriving segments for the development of fluorescent gelators. Carbz-4 and Carbz-5 were sparingly soluble or precipitated as crystals in most solvents studied. This can be explained by taking into account the strong intermolecular interactions of trans$(1 R, 2 R)$-diaminocyclohexane or cyclo(L-asparaginyl-L-phenylalanyl). Regarding fluorescent chromophores, the order of solubility was quinoline-containing gelators = benzothiazolecontaining gelators > carbazole-containing gelators (compare Carbz-4, Carbz-5, Quino-2, Quino-3, and Benth-2 in Table 1 and Table 2). Since both 8-hydroxyquinoline and 2-(2hydroxyphenyl)benzothiazole were miscible in ordinary solvents, unlike carbazole, the characteristics of the starting fluorescent materials were probably reflected in the solubility of their gelators. As for stilbene-containing gelators, Stilb-4 was a modestly good gelator, but Stilb-1, Stilb-2, and Stilb-3 were almost insoluble or precipitated as crystals in most of the solvents. The lack of gelating abilities for Stilb-1, Stilb-2, and Stilb-3 may arise from the absence of an appropriate hydrophile-lipophile balance.

\subsection{UV and fluorescence spectroscopy}

UV and fluorescence spectra of Carbz-1, Quino-1, Benth-1, Stilb-1, Stilb-2, and Stilb-3 measured in chloroform solutions at $1.0 \mathrm{mM}$ are shown in Figure S1. The absorption peaks of Carbz$\mathbf{1}$ are at 332 and $346 \mathrm{~nm}$ (Figure S1a). The fluorescence peaks were observed at 355 and $370 \mathrm{~nm}$, according to the Stokes shift. The absorbance and fluorescence peaks for Carbz-2, Carbz-3, Carbz-4, and Carbz-5 were almost the same as for Carbz-1. The wavelengths of the absorbance and fluorescence spectra maxima, $\lambda_{\max }$, of Quino-1, Quino-2, Quino-3, and Quino-4 are found at 306 and $392 \mathrm{~nm}$, respectively (Figure S1b). As shown in Figure S1c, benzothiazole-containing gelators (Benth-1, Benth-2, and Benth-3) reveal three absorption peaks at 300, 326, and $338 \mathrm{~nm}$, and three fluorescence peaks at 356, 368, and 386 $\mathrm{nm}$. With respect to stilbene-containing gelators (Stilb-1, Stilb2, Stilb-3, and Stilb-4), their absorbance and fluorescence spectra are quite different because of the dissimilar substituent groups attached to the stilbene unit. The spectra of Stilb-1 and Stilb-3 are shown in Figure S1d and S1e. TNT or RDX was detected by monitoring the fluorescence quenching of the aforementioned fluorescence $\lambda_{\max }$ peaks.

3.3. Fluorescent sensors of thin-layer films for detecting TNT Thin-layer sensors were prepared by directly drop-casting the gels or solutions onto quartz plates, followed by spin-coating and drying in vacuo. Gelation by low-molecular-weight compounds occurs via the self-aggregation of molecules driven by noncovalent bonding, resulting in the formation of fibrous aggregates. The fibrous aggregates ultimately form a 3D network structure in which solvent molecules are trapped. Thus, nanosized fibrous aggregates inevitably form during the initial stage of gelation. Hence, it is reasonable to assume that the fibrous aggregates will be fixed in thin-layer films prepared from low-molecular-weight gelators. The high surface area resulting from the formation of fibrous aggregates is an advantage for sensor applications.

The sensing abilities of the thin layers were studied by exposing them to TNT-saturated vapor. Figure 1 shows the fluorescence quenching of thin layers (thickness $\sim 70 \mathrm{~nm}$ ) of Carbz-1, Carbz-3, Carbz-4, Carbz-5, and carbazole upon exposure to saturated TNT vapor (vapor pressure $\sim 5.0 \mathrm{ppb}$ ) for different time periods. The thin-layer films in Figure 1 were prepared from the corresponding chloroform solutions. The excitation wavelength was $346 \mathrm{~nm}$ and the fluorescencemonitoring wavelength was $355 \mathrm{~nm}$. The fluorescencequenching efficiencies of the thin-layer film of Carbz-4 were $\sim 60 \%$ and $100 \%$ after exposure to TNT for 2 and $40 \mathrm{~min}$, respectively. Nearly the same behavior was observed for a thin layer (thickness $\sim 70 \mathrm{~nm}$ ) formed from the ethanol gel of Carbz4; the fluorescence-quenching efficiencies were $~ 76 \%$ and $96 \%$ for 2 and $30 \mathrm{~min}$ exposures, respectively. When the thin-layer film of Carbz-1 was exposed to the saturated vapor of TNT, a $\sim 73 \%$ reduction in fluorescence intensity was observed after exposure for $60 \mathrm{~min}$. Note that the TNT fluorescence-quenching efficiency of films prepared by drop-casting from the chloroform solution of carbazole was limited to $\sim 41 \%$, even after $60 \mathrm{~min}$. As mentioned later, the thin layer formed from the chloroform solution of carbazole was of a microcrystalline nature and was not a xerogel. Figure 1 indicates that the fluorescence-quenching efficiency decreases in the order Carbz-4 $>$ Carbz-1 $>$ Carbz3 > Carbz-5 $>$ carbazole.

We used DFM to characterize the morphologies of the thin layers prepared by direct drop-casting. Figure 2 shows the DFM images of the thin layers prepared from the chloroform solutions of Carbz-1, Carbz-3, Carbz-4, Carbz-5, and carbazole. The thin layer of carbazole, unsurprisingly, exhibited punctate crystalline nanostructures. The thin layers of carbazolecontaining gelators, which exhibited quenching when exposed to TNT, exhibited 3D networks of juxtaposed and interlocked fibers with widths of 50-300 nm. Although Carbz-4 could not gel chloroform (see Table 1), the DFM images exhibited dense entangled fibrous aggregates with very uneven surfaces, but not microcrystals. The formation of dense 3D fibrous networks with average widths of $30 \mathrm{~nm}$ was observed in the DFM image; the fiber diameters were nearly homogeneous. The height profiles of selected regions exhibit fibers with widths of several tens of nanometers, and heights in the range $10-20 \mathrm{~nm}$, with the fibers rising on the wafer. The effective quenching of the films obtained from chloroform solutions of carbazole-containing gelators and the formation of dense 3D fibrous networks suggest that these fluorescent gelators formed fibrous aggregates in chloroform, despite failing to physically gelate. The thin-layer films of carbazole-containing gelators have high surface areas compared with that of carbazole. The high surface areas can successfully come into contact with the explosive vapors, resulting in effective quenching.

The relationship between the thickness of the thin-layer films and the fluorescence-quenching efficiency was measured. The fluorescence-quenching efficiencies of thin-layer films obtained from the ethanol gel of Carbz-1 with different thicknesses (70-2700 nm) after 2 min of exposure to TNT were studied (Figure S2). The fluorescence-quenching efficiency markedly decreased with increasing film thickness. The quenching efficiency decreased from $71 \%$ for a film thickness of $70 \mathrm{~nm}$ to $\sim 10 \%$ for a thickness of $200 \mathrm{~nm}$. This result can be explained by considering the residual molecules deep within the thick films, which are not quenched by exposure to TNT. Thus, we can reasonably assume that thinner films exhibit more effective fluorescence quenching. It should be mentioned that when the thin-layer film thickness is less than $20 \mathrm{~nm}$, the fluorescence is too weak to detect. Choosing fluorescent materials having a large emission intensity may be important for sensors to detect TNT, because the thickness of the layers could 
then be reduced.

Next, we studied quinoline-containing gelators as chemosensors. Figure 3 shows the fluorescence quenching of the thin-layer films (thickness $\sim 70 \mathrm{~nm}$ ) obtained from chloroform solutions of Quino-1, Quino-2, Quino-3, and Quino-4 upon exposure to saturated TNT vapor. Here the excitation wavelength and the fluorescence wavelength for monitoring were $306 \mathrm{~nm}$ and $392 \mathrm{~nm}$, respectively. Quino-1 showed the best quenching efficiency among the quinoline-containing gelators; however, the fluorescence quenching was limited to $~ 89 \%$ after exposure for $30 \mathrm{~min}$. The quenching efficiencies of films comprising quinoline-containing gelators were low compared with carbazole-containing gelators. The fluorescence quenching of the thin-layer films obtained from chloroform solutions of Benth-1, Benth-2, and Benth-3 was also studied (Figure S3). The excitation wavelength was $326 \mathrm{~nm}$ and the fluorescence wavelength for monitoring was $365 \mathrm{~nm}$. It is noteworthy that the thin-layer film obtained from the chloroform solution of Benth1 showed 100\% quenching after $60 \mathrm{~min}$; however, the quenching efficiencies of benzothiazole-containing gelators were unremarkable when compared with carbazole-containing gelators.

Figure 4 shows the fluorescence quenching of the thin-layer films of stilbene-containing gelators. The excitation wavelengths for Stilb-1, Stilb-2, Stilb-3, and Stilb-4 were 350, 344, 334, and $340 \mathrm{~nm}$, respectively. Their fluorescence wavelengths for monitoring were 430, 425, 398, and $425 \mathrm{~nm}$, respectively. The fluorescence-quenching efficiencies of the thin-layer film (thickness $\sim 70 \mathrm{~nm}$ ) obtained from the toluene gel of Stilb-1 upon exposure to saturated TNT vapor were $~ 37 \%$ and $96 \%$ for 2 and $40 \mathrm{~min}$, respectively. The fluorescence-quenching efficiency decreased in the order Stilb-1 > Stilb-4 > Stilb-2 > Stilb-3. The quenching efficiency of Stilb-1 was better than that of the other stilbene-containing gelators.

Regarding the fluorescence quenching after exposure to saturated TNT vapor for $20 \mathrm{~min}$, the order of quenching efficiencies is: Carbz-2 (100\%, ethanol) > Carbz-4 (96\%, chloroform) $>$ Carbz-1 (94\%, ethanol) $>$ Stilb-1 (91\%, toluene) $>$ Carbz-3 (88\%, ethanol) > Benth-1 (79\%, chloroform) > Carbz-5 (75\%, toluene) $>$ Quino-1 (69\%, chloroform) $>$ Benth2 (65\%, chloroform) > Stilb-4 (62\%, toluene) > Stilb-2 (54\%, chloroform) > Stilb-3 (48\%, chloroform) > Benth-3 (46\%, chloroform) > Quino-3 (37\%, chloroform) > Quino-2 (19\%, chloroform), where the fluorescence-quenching efficiency and drop-casting solvents are shown in parentheses.

\subsection{Fluorescent chemosensors of thin-layer films for detecting RDX}

We studied the detection of the nonaromatic explosive RDX (hexahydro-1,3,5-trinitro-1,3,5-triazine). Figure 5 shows the fluorescence-quenching efficiencies of the thin-layer films (thickness $\sim 70 \mathrm{~nm}$ ) of Carbz-4, Quino-1, and Benth-1 upon exposure to saturated RDX vapor for different time periods. The thin-layer films were prepared by drop-casting from the chloroform solutions. The fluorescence-quenching efficiencies of the thin-layer film of Quino-1 were $~ 46 \%$ and $50 \%$ for 20 and $60 \mathrm{~min}$ exposures, respectively. Despite the very low vapor pressure $\left(\sim 5 \times 10^{-3} \mathrm{ppb}\right)$ of saturated RDX, significant decreases in quenching efficiency were observed for the thin-layer films of the Quino-1 and Benth-1 gelators; their quenching efficiencies were both $\sim 50 \%$ after $60 \mathrm{~min}$. Carbazole, compared with quinoline and benzothiazole, may be unsuitable as a chromophore for sensing RDX. The fluorescence-quenching efficiency upon exposure to RDX is surprising because RDX has no absorption in the visible light region. The contact of RDX vapor with the thin-layer films and the subsequent oxidative decomposition of the fluorescent gelators may be the cause of the fluorescence quenching. The cause for quenching by RDX requires further investigation considering the HOMO-LUMO energy levels, excitation energy, and energy of ionization.

\subsection{Fluorescence quenching upon exposure to nonexplosive aromatic compounds}

Fluorescence quenching of the thin-layer film prepared from the ethanol gel of Carbz-1 was studied in the presence of nonexplosive aromatic compounds. Figure 6 shows the fluorescence quenching when exposed to saturated DNT (2,4dinitrotoluene), nitrobenzene, terephthalonitrile, and $p$ dimethoxybenzene. The vapor pressures of DNT, nitrobenzene, terephthalonitrile, and p-dimethoxybenzene are $\sim 380 \mathrm{ppb}, 198$ ppm, 7.5 ppm, and 100 ppm, respectively. When the thin-layer film was exposed to saturated vapors of DNT, the fluorescencequenching efficiencies were $\sim 92 \%$ and $100 \%$ for 10 and $20 \mathrm{~min}$ exposures, respectively. The fluorescence was also quenched by exposure to nitrobenzene. Despite the low vapor pressure ( 380 $\mathrm{ppb})$ of DNT compared with nitrobenzene ( 198 ppm), the fluorescence-quenching rate by DNT was comparatively fast. These results indicate that the number of nitro groups is more important than the vapor pressure. On the other hand, the fluorescence-quenching rate by terephthalonitrile (7.5 ppm) with two electron-withdrawing cyano groups was slow, and quenching by $p$-dimethoxybenzene with two electron-donating methoxy groups was almost undetectable. The compounds with oxidative electron-withdrawing groups such as nitro groups seem to be effectively detected.

\subsection{Variable-temperature UV-vis spectroscopy}

To confirm that the fluorescence chromophore was situated in the gels, solutions, and thin-layer films, we measured their UVvis spectra. The spectrum of the ethanol gel $(10 \mathrm{mM})$ of Carbz$\mathbf{1}$ at $25^{\circ} \mathrm{C}$ was characterized by absorption peaks at wavelengths of 350 and $336 \mathrm{~nm}$. The absorption peaks of a thin-layer film of xerogel prepared from the ethanol gel $(10 \mathrm{mM})$ of Carbz-1 were observed at 352 and $336 \mathrm{~nm}$. The spectrum of the ethanol solution $(10 \mathrm{mM})$ at $60^{\circ} \mathrm{C}$ was characterized by absorption peaks at 344 and $330 \mathrm{~nm}$. The slight red-shift of the gel and xerogel states compared with the solution spectrum at $60^{\circ} \mathrm{C}$ suggests that there is an interaction, such as J-aggregate formation, between the carbazole units in Carbz-1 in the gel and xerogel states. Nearly the same behavior was observed in the case of Carbz-2.

We studied the interaction of the stilbene chromophore in Stilb-1, Stilb-2, Stilb-3, and Stilb-4 by variable-temperature UV-vis spectroscopy (Figure S4). Stilb-1, Stilb-2, Stilb-3, and Stilb-4 could form translucent gels in $\gamma$-butyrolactone, dodecane, toluene, and DMF at $5 \mathrm{mM}$, respectively. Gels that formed at $25^{\circ} \mathrm{C}$ transformed into the corresponding isotropic solutions at $85^{\circ} \mathrm{C}$. The peak absorption wavelength of Stilb-4 was almost unchanged when gels formed upon cooling the solutions. The peak absorption wavelength of $364 \mathrm{~nm}$ in the solution of Stilb-1 at $85^{\circ} \mathrm{C}$ was slightly red-shifted to $362 \mathrm{~nm}$ in the gel state at $25^{\circ} \mathrm{C}$. On the contrary, for Stilb-2, the peak absorption wavelength of $322 \mathrm{~nm}$ in the solution at $85^{\circ} \mathrm{C}$ was significantly blue-shifted to $296 \mathrm{~nm}$ in the gel state at $25^{\circ} \mathrm{C}$. A large blue-shift was also observed in Stilb-3; the peak at $324 \mathrm{~nm}$ in the solution at $85^{\circ} \mathrm{C}$ was blue-shifted to $308 \mathrm{~nm}$ in the gel state at $25^{\circ} \mathrm{C}$. The large blue-shifts of Stilb-2 and Stilb-3 accompanied by gelation suggest the existence of $\pi-\pi$ stacking among the stilbene units in the gels, which is similar to that in an H-aggregate. The lack of observation of significant shifts in the peak absorption wavelengths of Stilb-1 and Stilb-4 when gels were formed indicates disordered stilbene units in the gels. Since the fluorescence-quenching rate decreased in the order Stilb-1 > 
Stilb-4 > Stilb-2 > Stilb-3 (Figure 6), the dispersal of chromophores in a disordered manner seems to be important for effective fluorescence quenching.

\subsection{Mechanism of TNT detection}

HOMO and LUMO energies were measured to study the mechanism of TNT detection. The HOMO and LUMO energies of carbazole, Carbz-1, Carbz-3, Carbz-4, and Carbz-5 are summarized in Table 3. The HOMO levels were determined by measuring the ionization potential (IP). The LUMO levels are calculated from the IP and band-gap energies estimated from the UV-vis spectra. The HOMO and LUMO levels of carbazole were -5.80 and $-2.18 \mathrm{eV}$, respectively, whereas those of Carbz-1, Carbz-3, Carbz-4, and Carbz-5 were calculated to be $\sim-5.8 \mathrm{eV}$ and $\sim-2.2 \mathrm{eV}$, respectively. These results suggest that the HOMO and LUMO levels of the carbazole unit are mostly uninfluenced by the connection of gelation-driving segments. Energy calculations with optimized geometries were carried out using density functional theory at the B3LYP/6-31G* level for the TNT molecule. The HOMO and LUMO energies of TNT were -8.7 and $-3.8 \mathrm{eV}$, respectively. The HOMO and LUMO energy levels of carbazole, Carbz-1, Carbz-3, Carbz-4, Carbz-5, and TNT are shown in Figure 7. Photoinduced electron transfer from carbazole and the fluorescent gelators to TNT is clearly possible, resulting in fluorescence quenching. Despite the almost identical HOMO and LUMO energies of carbazole, Carbz-1, Carbz-3, Carbz-4, and Carbz-5, an obvious difference in the fluorescence-quenching efficiency was observed: Carbz-4 > Carbz-1 > Carbz-3 > Carbz-5 > carbazole (Figure 1). These results indicate that the morphology of the thin-layer films plays an important role. The high surface areas can successfully come into contact with TNT vapor, resulting in effective quenching.

\section{Conclusion}

New compounds containing carbazole, quinoline, benzothiazole, and stilbene were prepared as fluorescent gelators. The obtained compounds could form physical gels in some solvents. Thin-layer films were prepared on quartz plates by drop-casting, and their abilities to detect explosives such as saturated TNT or RDX vapor were evaluated by fluorescence quenching. The fluorescence-quenching efficiencies of the thinlayer films of Carbz-4 were $\sim 60 \%$ and $100 \%$ after exposure to TNT for 2 and $40 \mathrm{~min}$, respectively. The fluorescence-quenching rate decreased in the order Carbz-4 > Carbz-1 > Carbz-3 > Carbz-5 > carbazole. The morphology, studied by DFM, of the thin-layer films obtained from the chloroform solution of carbazole was microcrystalline and was not a xerogel. The morphologies of the thin-layer films of Carbz-1, Carbz-3, Carbz-4, and Carbz-5 were 3D networks of juxtaposed and interlocked fibers with very uneven surfaces. Quino-1 showed the best quenching efficiency among the quinoline-containing gelators. Although the thin-layer film of Benth-1 showed 100\% quenching after $60 \mathrm{~min}$, the quenching efficiencies of benzothiazole-containing gelators were unremarkable when compared with carbazole-containing gelators. The fluorescencequenching efficiencies of the thin-layer film obtained from the toluene gel of Stilb-1 by TNT vapor were $\sim 37 \%$ and $96 \%$ for 2 and $40 \mathrm{~min}$ exposures, respectively. The fluorescence-quenching rate decreased in the order Stilb-1 $>$ Stilb-4 $>$ Stilb-2 $>$ Stilb-3. The fluorescence-quenching efficiency decreased distinctly with increasing film thickness. The fluorescence-quenching efficiency of Carbz-1 decreased from $71 \%$ for a film thickness of $70 \mathrm{~nm}$ to $\sim 10 \%$ for a thickness of $200 \mathrm{~nm}$. When the thin-layer film thickness was less than $20 \mathrm{~nm}$, the fluorescence was too weak to detect TNT. Despite the very low vapor pressure of saturated RDX, moderately good decreases ( $50 \%)$ in quenching efficiency were observed for thin-layer films of Quino-1 and Benth-1. The observed red-shift of the gel and xerogel states of Carbz-1 in UV-vis spectroscopy suggests an interaction similar to J-aggregation between carbazole units. The peak absorption wavelengths of Stilb-1 and Stilb-4 were almost unchanged when gels were formed upon cooling their heated solutions. This indicates disorder among the stilbene units in the gels. The peak absorption wavelengths of Stilb-2 and Stilb-3 in solutions at $85^{\circ} \mathrm{C}$ were significantly blue-shifted in the gel state at $25^{\circ} \mathrm{C}$, which suggests the existence of $\pi-\pi$ stacking similar to $\mathrm{H}$-aggregation among the stilbene units in the gels. The estimated HOMO and LUMO energy levels of carbazolecontaining gelators and TNT indicate that photoinduced electron transfer from fluorescent gelators to TNT is possible.

\section{Acknowledgement}

The present research was supported in part by JSPS KAKENHI Grant Number JP15K05623.

\section{References}

1. A. Narayanan, O. P. Varnavski, T. M. Swager, J. Phys. Chem. C 2008, 112, 881.

2. C. Vijayakumar, G. Tobin, W. Schmitt, M.-J. Kim, M. Takeuchi, Chem. Commun. 2010, 46, 874.

3. Y. Yang, H. Wang, K. Su, Y. Long, Z. Peng, N. Li, F. Liu, J. Mater. Chem. 2011, 21, 11895.

4. C. Zhang, Y. Che, X. Yang, B. R. Bunes, L. Zang, Chem. Commun. 2010, 46, 5560.

5. H. Nie, Y. Zhao, M. Zhang, Y. Ma, M. Baumgarten, K. Müllen, Chem. Commun. 2011, 47, 1234.

6. H. Nie, G. Sun, M. Zhang, M. Baumgarten, K. Müllen, J. Mater. Chem. 2012, 22, 2129.

7. Z. Ding, Q. Zhao, R. Xing, X. Wang, J. Ding, L. Wang, Y. Han, J. Mater. Chem. C 2013, 1, 786.

8. K. K. Kartha, S. S. Babu, S. Srinivasan, A. Ajayaghosh, J. Am. Chem. Soc. 2012, 134, 4834.

9. N. Dey, S. K. Samanta, S. Bhattacharya, ACS Appl. Mater. Interfaces 2013, 5, 8394.

10. P. Terech, R. G. Weiss, Chem. Rev. 1997, 97, 3133.

11. J. H. Esch, B. L. Feringa, Angew. Chem., Int. Ed. 2000, 39, 2263.

12. L. A. Estroff, A. D. Hamilton, Chem. Rev. 2004, 104, 1201.

13. P. Dastidar, Chem. Soc. Rev. 2008, 37, 2699.

14. S. Banerjee, R. K. Das, U. Maitra, J. Mater. Chem. 2009, 19, 6649.

15. M. Suzuki, K. Hanabusa, Chem. Soc. Rev. 2009, 38, 967.

16. M. Suzuki, K. Hanabusa, Chem. Soc. Rev. 2010, 39, 455.

17. J.-L. Li, X.-Y. Liu, Adv. Funct. Mater. 2010, 20, 3196.

18. G. John, B. V. Shankar, S. R. Jadhav, P. K. Vemula, Langmuir 2010, 26, 17843.

19. H. Svobodová, V. Noponen, E. Kolehmainen, E. Sievänen, RSC Adv. 2012, 2, 4985.

20. S. S. Babu, S. Prasanthkumar, A. Ajayaghosh, Angew. Chem., Int. Ed. 2012, 51, 1766.

21. A. Y.-Y. Tam, V. W.-W. Yam, Chem. Soc. Rev. 2013, 42, 1540.

22. J. Raeburn, A. Z. Cardoso, D. J. Adams, Chem. Soc. Rev. 2013, 42, 1543.

23. G. Yu, X. Yan, C. Han, F. Huang, Chem. Soc. Rev. 2013, 42, 6697.

24. M. D, Segarra-Maset, V. J. Nebot, J. F. Miravet, B. Escuder, Chem. Soc. Rev. 2013, 42, 7086.

25. S. S. Babu, V. K. Praveen, A. Ajayaghosh, Chem. Rev. 2014, 114, 1973.

26. D. K. Kumar, J. W. Steed, Chem. Soc. Rev. 2014, 43, 2080.

27. V. K. Praveen, C. Ranjith, N. Armaroli, Angew. Chem., Int. 
Ed. 2014, 53, 365.

28. Y. Lan, M. G. Corradini, R. G. Weiss, S. R. Raghavanc, M. A. Rogers, Chem. Soc. Rev. 2015, 44, 6035.

29. X. Li, J. Li, Y. Gao, Y. Kuang, J. Shi, B. Xu, J. Am. Chem. Soc. 2010, 132, 17707.

30. J. Li, Y.Gao, Y. Kuang, J. Shi, X. Du, H. Wang, Z. Yang, B. Xu, J. Am. Chem. Soc. 2013, 135, 9907.

31. L. Chronopoulou, A. R. Togna, G. Guarguaglini, G. Masci, F. Giammarco, G. I. Togna, C. Palocci, Soft Matter. 2012, 8, 5784.

32. B. F. Lin, K. A. Megley, N. Viswanathan, D. V. Krogstad, L. B. Drews, M. J. Kade, Y. Qian, M. V. Tirrell, J. Mater. Chem. 2012, 22, 19447.

33. K. Murata, M. Aoki, T. Nishi, A. Ikeda, S. Shinkai, Chem. Commun. 1991, 1715.

34. J. J. D. de Jong, L. N. Lucas, R. M. Kellogg, J. H. van Esch, B. L. Feringa, Science 2004, 304, 278.

35. J. Chen, W. Wu, A. J. McNeil, Chem. Commun. 2012, 48, 7310.

36. P. Xue, Q. Xu, P. Gong, C. Qian, A. Ren, Y. Zhang, R. Lu, Chem. Commun. 2013, 49, 5838.

37. Y. Ono, K. Nakashima, M. Sano, Y. Kanekiyo, K. Inoue, J. Hojo, S. Shinkai, Chem. Commun. 1998, 1477.

38. H. Basit, A. Paul, S. Sen, S. Bhattacharya, Chem.-Eur. J. 2008, 14, 6534.

39. S. Kobayashi, K. Hanabusa, N. Hamasaki, M. Kimura, H. Shirai, S. Shinkai, Chem. Mater. 2000, 12, 1523.

40. S. Kobayashi, N. Hamasaki, M. Suzuki, M. Kimura, H. Shirai, K. Hanabusa, J. Am. Chem. Soc. 2002, 124, 6550.

41. Y. Yang, M. Suzuki, H. Fukui, H. Shirai, K. Hanabusa, Chem. Mater. 2006, 18, 1324.

42. W. Kubo, S. Kambe, S. Nakade, T. Kitamura, K. Hanabusa, Y. Wada, S. Yanagida, J. Phys. Chem. B 2003, 107, 4374.

43. S. S. Babu, S. Prasanthkumar, A. Ajayaghosh, Angew. Chem., Int. Ed. 2012, 51, 1766.

44. K. Hanabusa, K. Hiratsuka, M. Kimura, H. Shirai, Chem. Mater. 1999, 11, 649.

45. K. Hanabusa, M. Suzuki, Bull. Chem. Soc. Jpn. 2016, 89, 174.

46. K. Hanabusa, T. Ueda, S.Takata, M. Suzuki, Chem. Eur. J. in contribution.

47. K. Hanabusa, H. Fukui, M. Suzuki, H. Shirai, Langmuir 2005, 21, 10383.

48. M. Suzuki, R. Yanagida, C. Setoguchi, H. Shirai, K. Hanabusa, J. Polym. Sci., Part A: Polym. Chem. 2008, 46, 353.

49. K. Hanabusa, K. Harano, M. Fujisaki, Y. Nomura, M. Suzuki, Macromolecular Sympo. 2016, 46, 353.

50. R. C. Dorey, W. R. Carper, J. Chem. Eng. Data 1984, 29, 93.

51. G. C. Hale, J. Am. Chem. Soc. 1925, 364, 7.

52. W. E. Bachmann, J. Sheehan, J. Am. Chem. Soc. 1949, 71, 1842. 


\section{Graphical Abstract}

$<$ Title $>$

Fluorescent gelators for detection of explosives

$<$ Authors' names>

Kenji Hanabusa, Shingo Takata, Masafumi Fujisaki, Yasushi Nomura, and Masahiro Suzuki

$<$ Summary $>$

Fluorescent gelators are synthesized and fibrous thin layer films are prepared on quartz plates. Fluorescence quenching of the films upon exposure to saturated TNT or RDX vapor is used to evaluate the abilities of the films to detect explosives.

$<$ Diagram $>$

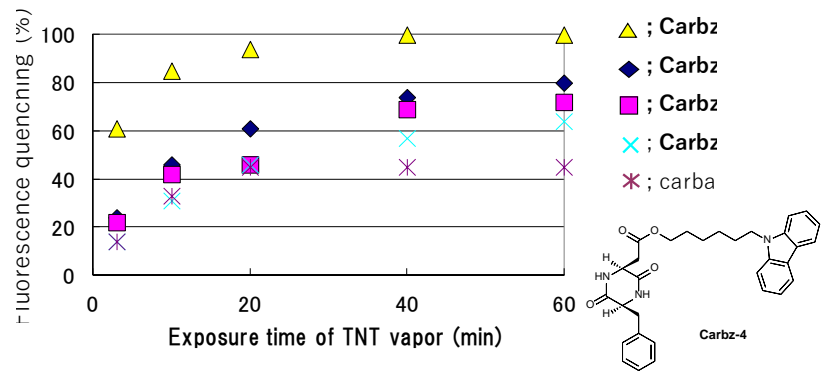


Table 1. Gelation test of carbazole- and quinoline-containing gelators at $25^{\circ} \mathrm{C}$.

\begin{tabular}{|c|c|c|c|c|c|c|c|c|c|}
\hline Solvent & Carbz-1 & Carbz-2 & Carbz-3 & Carbz-4 & Carbz-5 & Quino-1 & Quino-2 & Quino-3 & Quino-4 \\
\hline Hexane & I & I & I & I & I & I & I & I & I \\
\hline Dodecane & Gel & Gel & Gel & I & $\mathrm{P}$ & Gel & I & I & I \\
\hline Toluene & Gel & Gel & Gel & Gel & Gel & Gel & Gel & Gel & Gel \\
\hline Chloroform & S & S & S & S & S & S & S & $\mathrm{S}$ & S \\
\hline Ethyl acetate & Gel & Gel & Gel & I & I & Gel & Gel & $\mathrm{P}$ & Gel \\
\hline THF & S & S & $\mathrm{P}$ & I & $\mathrm{P}$ & S & S & $S$ & $S$ \\
\hline Acetone & Gel & $\mathrm{P}$ & $\mathrm{P}$ & I & I & Gel & $\mathrm{P}$ & $\mathrm{S}$ & $\mathrm{P}$ \\
\hline 1-Propanol & Gel & Gel & Gel & $\mathrm{P}$ & Gel & Gel & Gel & Gel & Gel \\
\hline Ethanol & Gel & Gel & Gel & I & $\mathrm{P}$ & Gel & Gel & $\mathrm{P}$ & Gel \\
\hline Methanol & Gel & Gel & Gel & I & I & Gel & $\mathrm{P}$ & $\mathrm{P}$ & $\mathrm{P}$ \\
\hline DMF & Gel & Gel & Gel & $\mathrm{P}$ & $\mathrm{P}$ & Gel & S & $\mathrm{S}$ & $\mathrm{S}$ \\
\hline$\gamma-B L$ & Gel & Gel & Gel & S & $\mathrm{S}$ & Gel & S & $\mathrm{S}$ & Gel \\
\hline DMSO & Gel & Gel & Gel & $\mathrm{P}$ & $\mathrm{P}$ & Gel & $\mathrm{S}$ & $\mathrm{S}$ & $\mathrm{P}$ \\
\hline
\end{tabular}


Table 2. Gelation test of benzothiazole- and stilbene-containing gelators at $25^{\circ} \mathrm{C}$.

\begin{tabular}{lccccccc}
\hline Solvent & Benth-1 & Benth-2 & Benth-3 & Stilb-1 & Stilb-2 & Stilb-3 & Stilb-4 \\
\hline Hexane & I & I & I & I & I & I & I \\
Dodecane & Gel & I & I & P & Gel & I & P \\
Toluene & Gel & Gel & Gel & Gel & P & Gel & Gel \\
Chloroform & S & S & S & S & S & S & S \\
Ethyl acetate & Gel & Gel & Gel & P & P & P & PG \\
THF & S & S & S & P & S & P & S \\
Acetone & Gel & P & P & P & P & I & Gel \\
1-Propanol & Gel & Gel & Gel & P & P & I & Gel \\
Ethanol & Gel & Gel & Gel & P & P & I & P \\
Methanol & Gel & P & P & P & P & I & P \\
DMF & Gel & S & S & P & S & P & Gel \\
$\gamma$-BL & Gel & S & Gel & Gel & P & Gel & Gel \\
DMSO & Gel & S & P & P & S & P & Gel
\end{tabular}

PG: Partially gel, P: Precipitation, S: Soluble, I: Almost insoluble, $\gamma$-BL: $\gamma$-Butyrolactone. The concentrations were fixed at $40 \mathrm{mg} \mathrm{mL}^{-1}$ (gelator/solvent). 
Table 3. HOMO and LUMO energy levels of carbazole and fluorescent gelators.

\begin{tabular}{ccc}
\hline Compounds & HOMO & LUMO \\
\hline carbazole & -5.80 & -2.18 \\
Carbz-1 & -5.82 & -2.14 \\
Carbz-3 & -5.75 & -2.15 \\
Carbz-4 & -5.88 & -2.31 \\
Carbz-5 & -5.62 & -2.10
\end{tabular}

HOMO energy levels were determined by measuring ionization potentials (IPs). LUMO energy levels were calculated from the IPs and band-gap energies estimated from UV-vis spectra. 


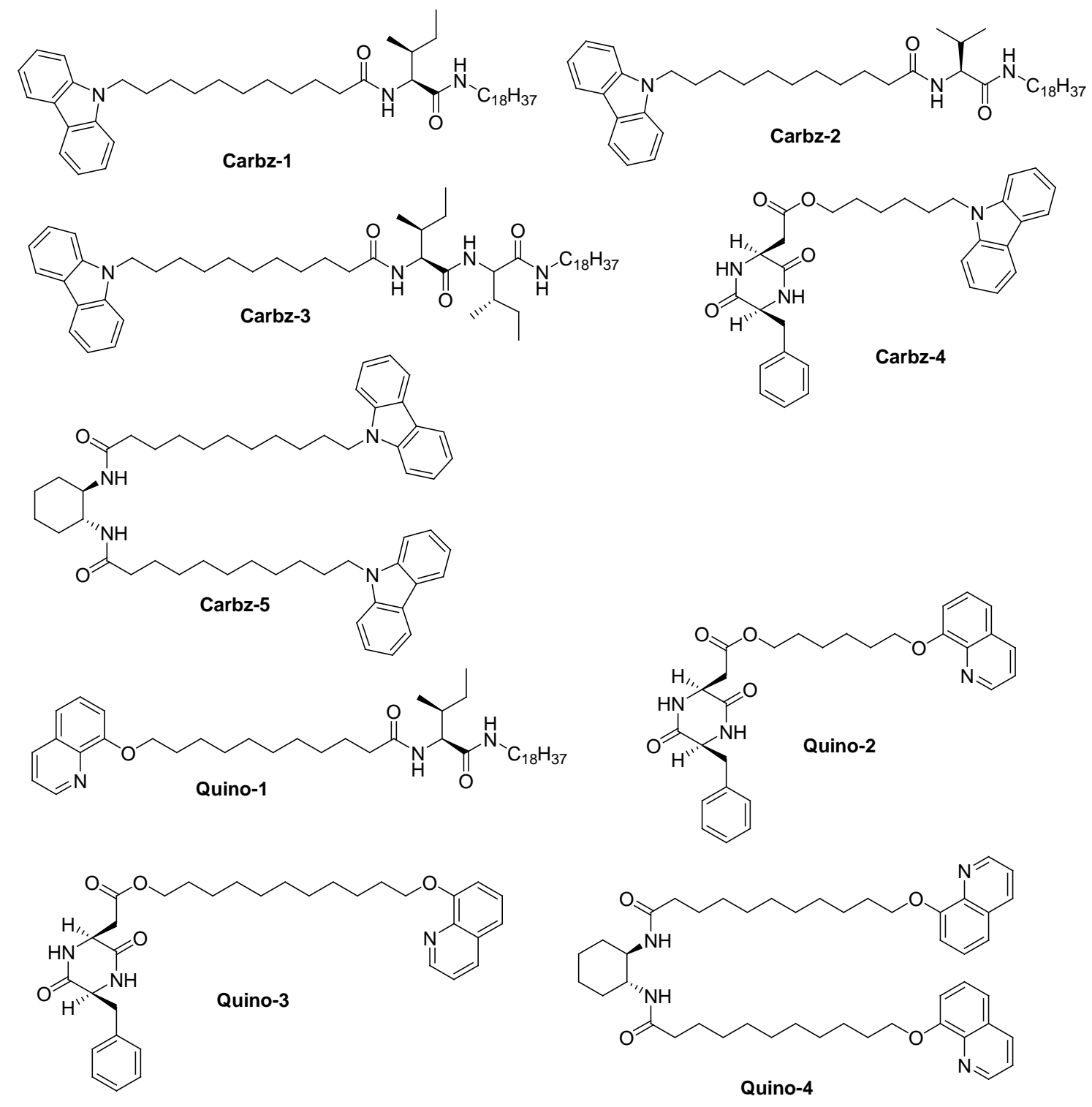

Scheme 1. Structures of Carbazole- and Quinoline-Containing Gelators 


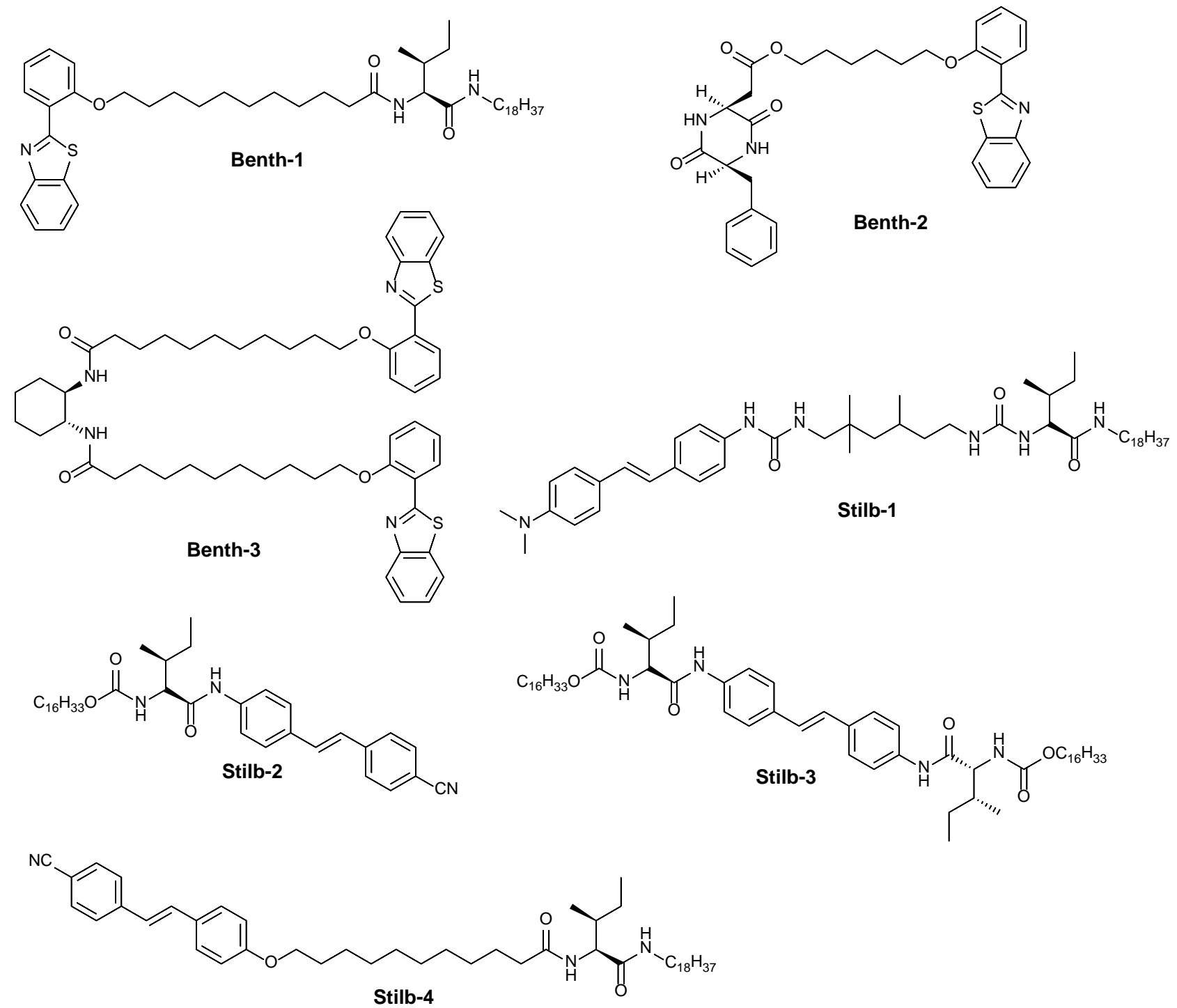

Scheme 2. Structures of Benzothiazole- and Stilbene-Containing Gelators 


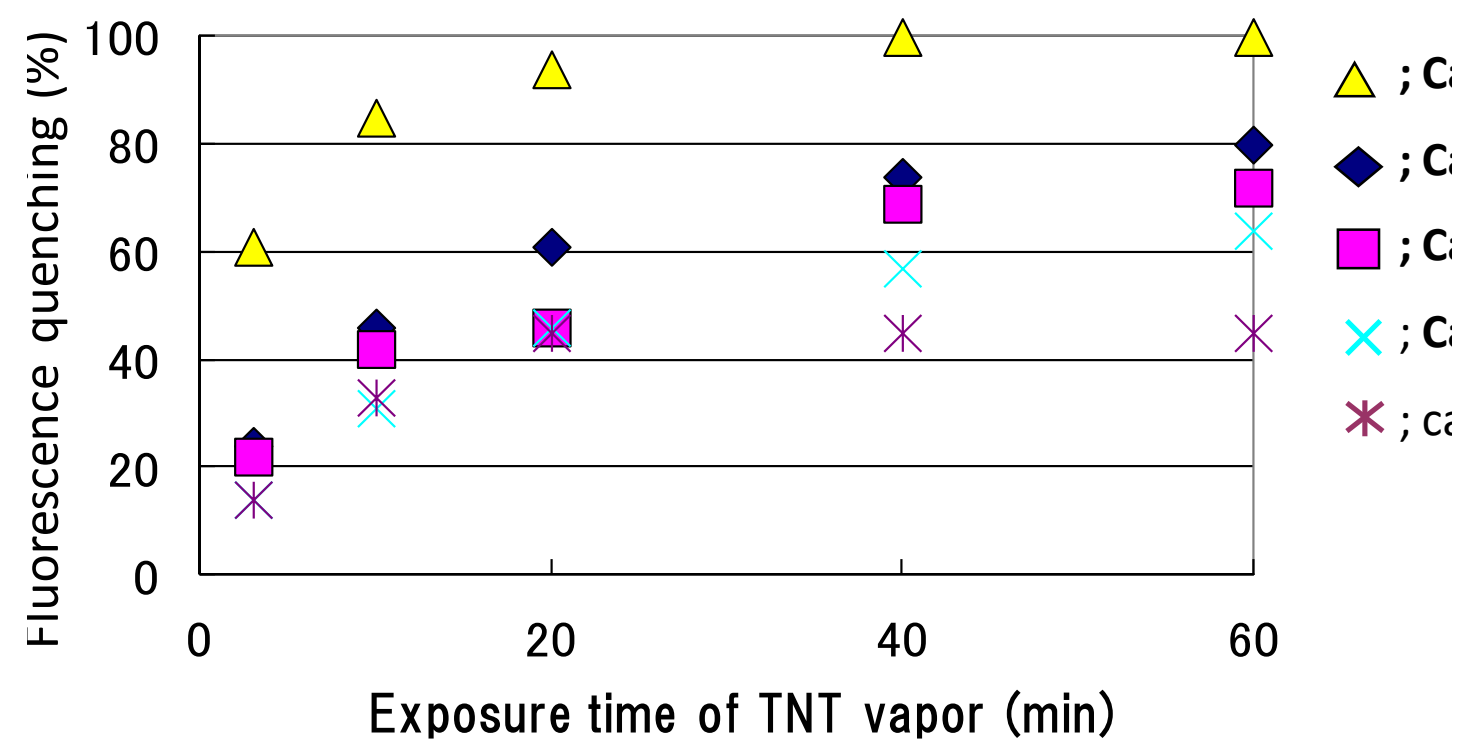

Figure 1. Fluorescence quenching of thin layers of Carbz-1, Carbz-3, Carbz-4, Carbz-5, and carbazole prepared by chloroform solution, when exposed to saturated TNT (ca.5.0 ppb) vapor. 


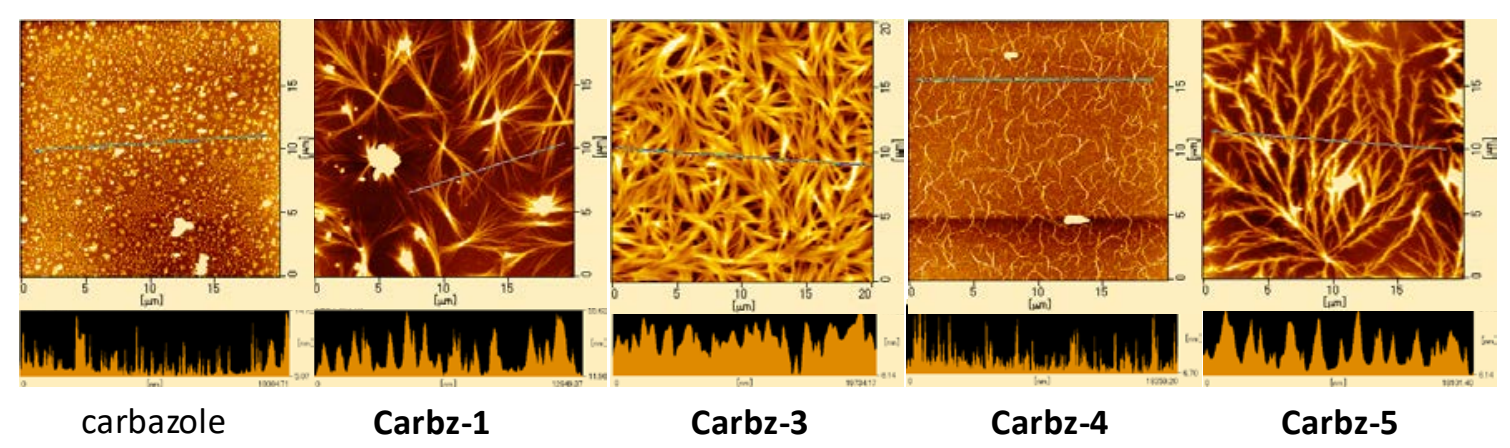

Figure 2. DFM images of thin layers prepared from chloroform solution (1mM). 


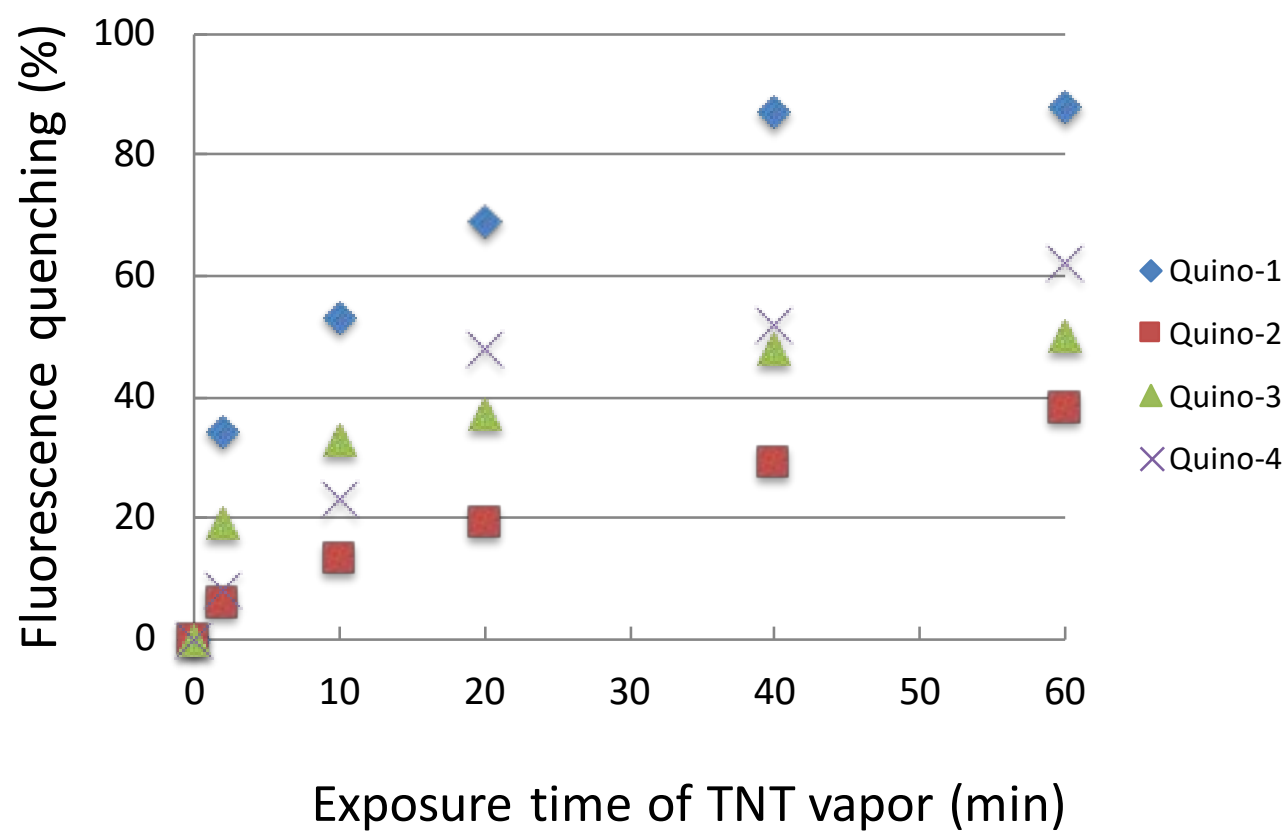

Figure 3. Fluorescence quenching of thin layers of Quino-1, Quino-2, Quino-3, and Quino-4, when exposed to saturated TNT (ca.5.0 ppb) vapor. 


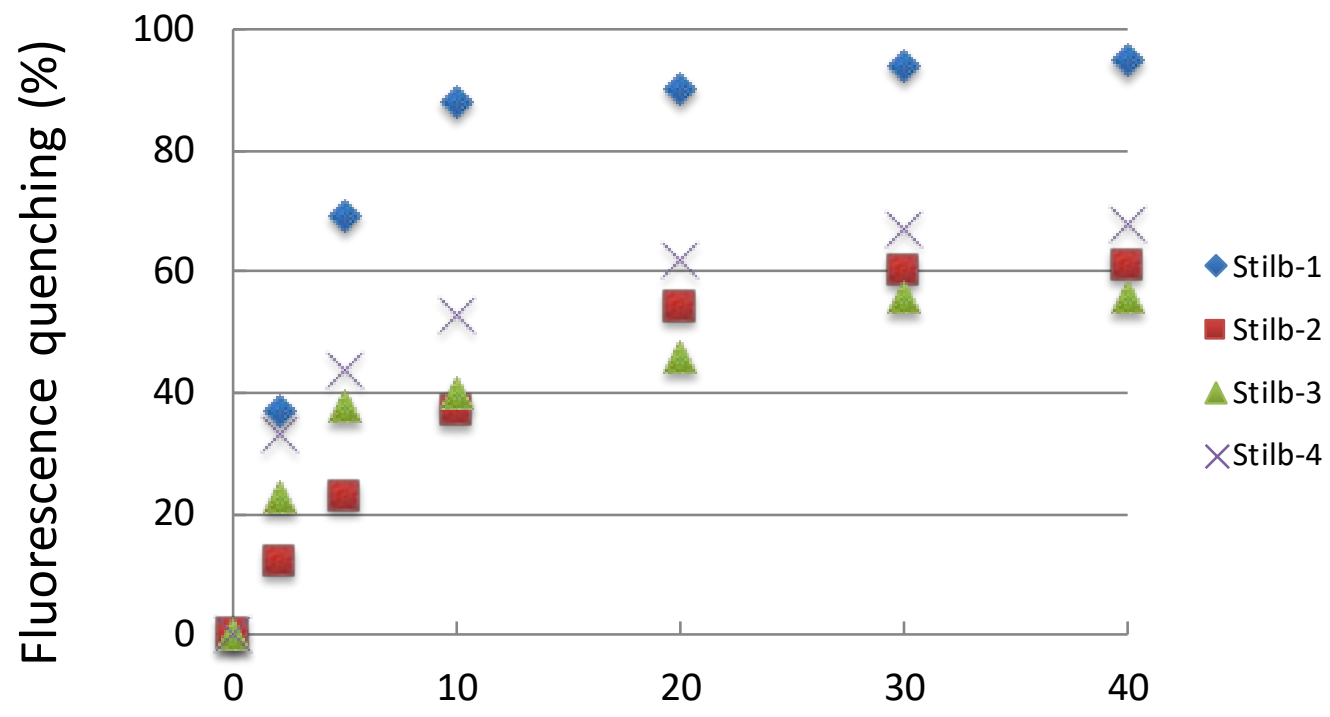

Exposure time of TNT vapor (min)

Figure 4. Fluorescence quenching of thin-layers of Stilb-1, Stilb-2, Stilb-3, and Stilb-4, when exposed to saturated TNT(ca.5.0ppb) vapor. 


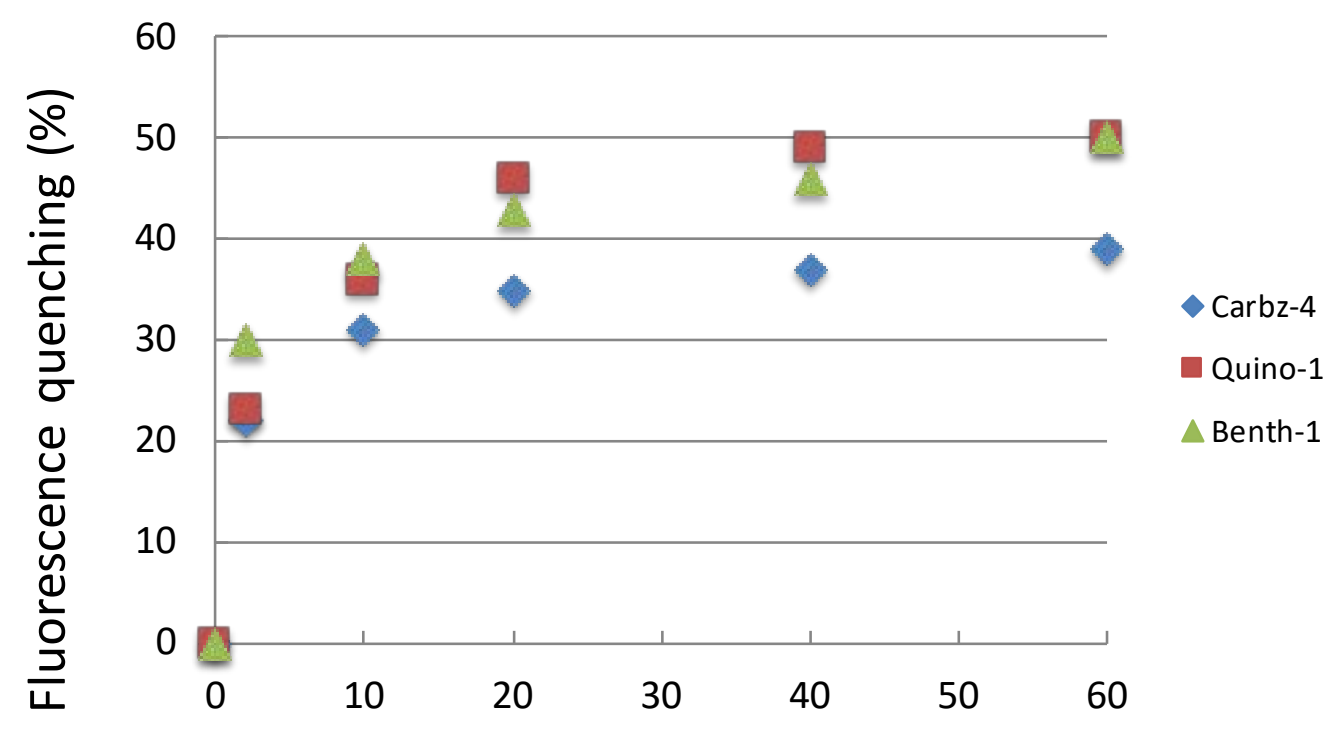

Exposure time of RDX vapor (min)

Figure 5. Fluorescence quenching of thin layers of Carbz-4, Quino-1, and Benth-1, when exposed to saturated RDX (ca.0.005 ppb) vapor. 


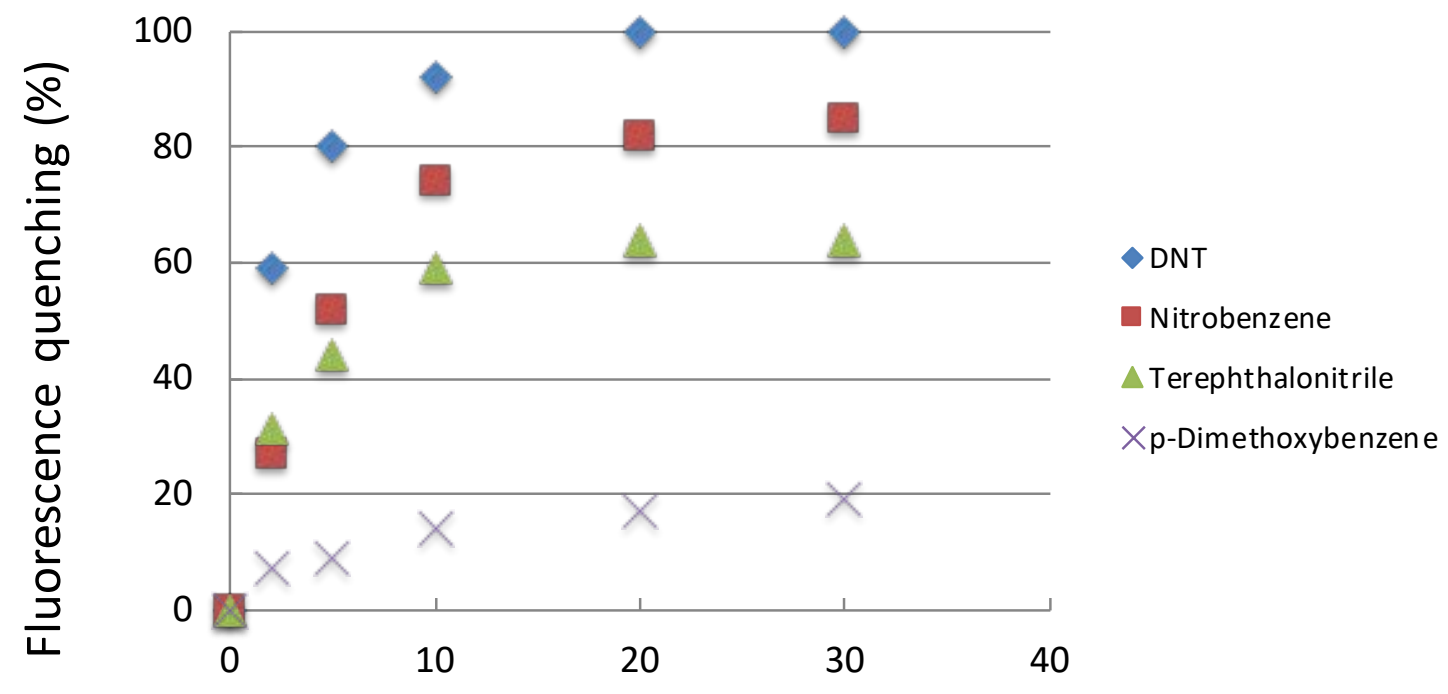

Exposure time of various aromatic compounds (min)

Figure 6. Fluorescence quenching of thin layers of Carbz-1, when exposed to saturated aromatic compounds' vapors. 


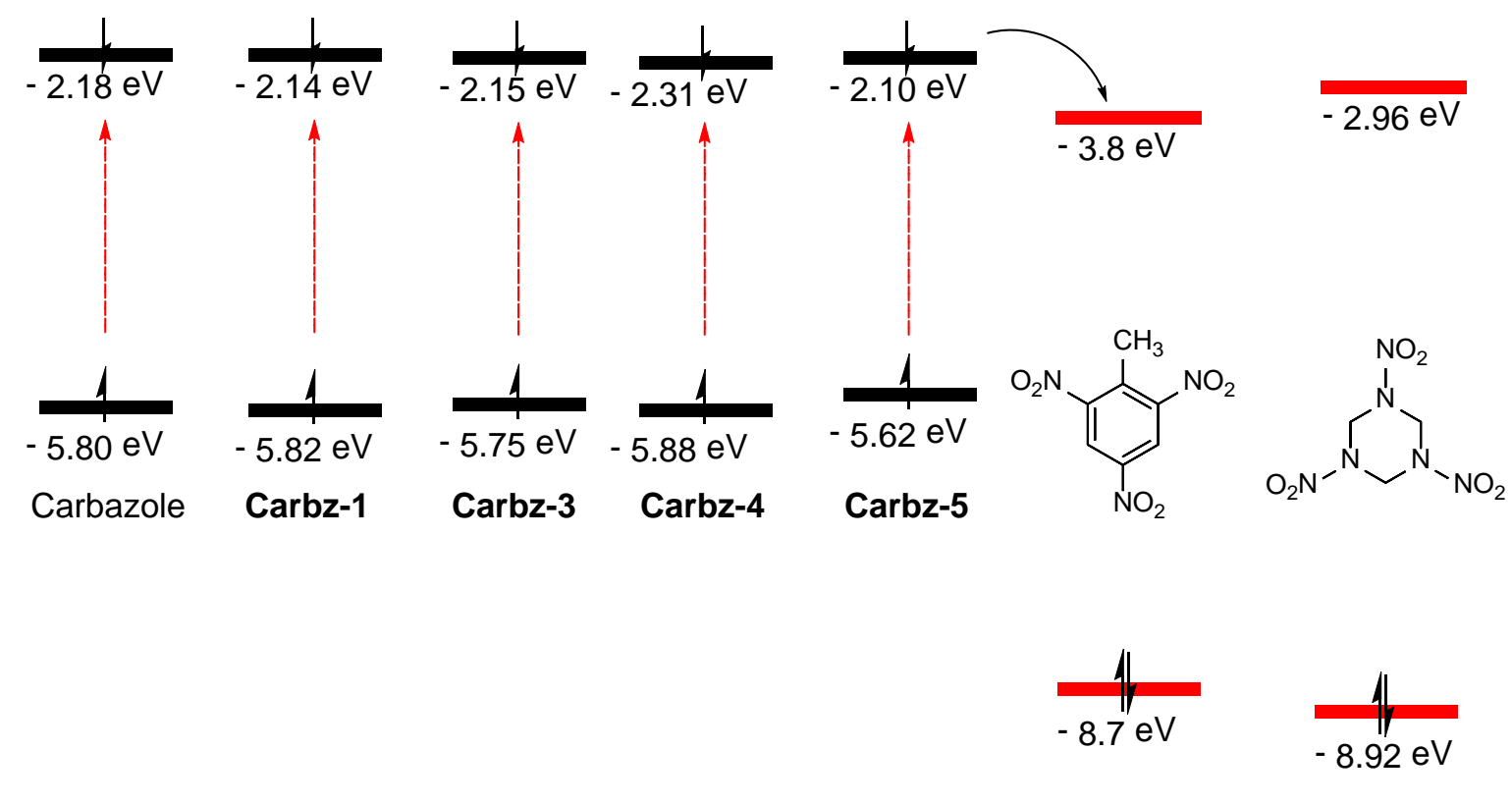

Figure 7. HOMO and LUMO energy levels of carbazole, Carbz-1, Carbz-3, Carbz-4, Carbz-5, and TNT. 